\title{
Analysis on the Communication of Visual Language of Hani Costume Patterns from the Perspective of 5W Mode Theory
}

\author{
Yang $\mathrm{Li}^{1, *}$ \\ ${ }^{1}$ Renwen Department, Xiamen Huaxia University, Xiamen, Fujian 361000, China \\ *Corresponding author. Email:304482495@qq.com
}

\begin{abstract}
The communication of Hani costume pattern visual language follows the process of communication subject (information source), communication content, communication object (audience), communication mode (media) and communication effect, namely " $5 \mathrm{~W}$ " communication mode. This paper analyzes the communication subject (information source) and communication object (audience) of Hani costume pattern visual language, and concludes that the communication subject (source) of visual language of Hani costume pattern is Hani people, and its communication object (audience) is people wearing Hani costume and seeing these clothes. From three aspects of function, connotation and aesthetics, this paper summarizes the communication content of Hani costume pattern visual language. From the perspective of "5W mode" theory, this paper analyzes the communication characteristics and process of Hani costume pattern visual language, and concludes that Hani costume pattern visual language is a complex communication.
\end{abstract}

Keywords: 5W communication mode theory, Visual language communication, Hani costume patterns.

\section{INTRODUCTION}

Lasswells, an American communication scholar and founder of communication studies, published an article "The Structure and Function of Communication in Society" in 1948, and proposed the famous "5W model" theory, that is, the communication subject (source), communication content, communication target (audience), communication method (media) and communication effect constitute a complete communication process.[1]

The patterns on the Hani costume are exquisite and beautiful, and have their unique symbolic meaning. We recognize the Hani costume patterns as a visual language that can be spread. The communication mode of this visual language also follows the "5W" mode. The visual language of Hani costume patterns is a popular and traditional

*Project: Social planning project of Fujian Province in 2018(Project No.: FJ2018C016). Project of Higher Education Research Institute of Xiamen Huaxia University(Project No.: HXGJ2019013). way of communication. Although the mode of communication has undergone revolutionary changes and is becoming more and more abundant, the original communication mode of the visual language of Hani costume patterns is still worth studying, which is of great significance to the protection of intangible cultural heritage. There are many studies on Hani costumes and patterns in academic circles. Some documents introduce Hani costumes, male costumes, and female costumes that change with age. Some authors focus on the clothing and hairstyles of women from the Yiche branch. Scholar Li Qibo analyzed the Hani's costume types and clothing decoration methods. Yang Xiao, a researcher at the Yunnan Nationalities Museum, summarized the characteristics of Hani costumes as "simplicity and timelessness, complex and rich charm. A large number of scholars have done research on the costume style, aesthetics and cultural connotation of the Hani nationality. In the article "Study on the Art of Hani Costume Patterns"[2], the author focuses on analyzing the patterns and connotations of Hani costumes. 
This article innovatively recognizes the patterns of Hani costumes as a visual language, and analyzes its communication mode from the perspective of communication.

The visual language of Hani costume patterns must be attached to a certain entity. Just as stated in the theory of communication, the information of visual language must be attached to a specific substance. All visual language information is dependent on a certain entity to produce, send, and Received and utilized. What the communication subject (source) sends and the communication object receives is not pure information, but a certain material form that carries information. This material is called information carrier or media, and the information carrier of the Hani costume pattern is the Hani national costume. The medium (dissemination method) is the carrier and media for disseminating information, and is an important link in the process of the $5 \mathrm{~W}$ dissemination model. Information dissemination will inevitably pass through certain media, and the media must also transmit certain information. The visual language of Hani costume patterns is spread through the medium of costumes. In the following, we will analyze the communication process of the visual language of Hani costumes from the aspects of the communication subject (source), communication target (audience), and communication content.

\section{COMMUNICATION SUBJECT (SOURCE) AND OBJECT (AUDIENCE) OF VISUAL LANGUAGE OF HANI COSTUME PATTERNS}

From the perspective of $5 \mathrm{~W}$ mode, the communication subject (source) of Hani costume pattern visual language needs to be analyzed first. At that time, in the context of visual language communication of Hani costume patterns, the public had dual identities in the process of information dissemination. They were not only the source of information (communication subject), but also the information receiver (communication object and audience), so we should pay attention to the communication subject and communication object of Hani costume pattern visual language. The communication subject (source) of visual language of Hani costume patterns is Hani people, who created this mysterious and beautiful visual language. People wearing Hani costume and seeing these costumes are its communication objects (audience).

\section{COMMUNICATION CONTENT OF VISUAL LANGUAGE OF HANI COSTUME PATTERNS}

In order to understand the transmission of visual language of Hani costume patterns, we must analyze its communication content. The research of Hani costume pattern visual language communication content is the basis of its communication process. The content of visual language of Hani costume patterns is very diverse. This paper analyzes the visual language of Hani costume patterns from three aspects of function, connotation and aesthetics.

\subsection{The Function of Visual Language of Hani Costume Patterns}

The pattern has its function. The main function of Hani costume pattern visual language at the beginning of its birth is to inherit and record history. The "ABO" in the costume patterns of Hani nationality is actually the language, recording the history of Hani nationality. Today's Hani people do not have their own written words, but it is said that the Aini branch of Hani nationality once had their own written words. The original writing of Hani people is called "ABO". Only one couple of Aini branch mastered this kind of written words and hid them in their bamboo house. One of the couple's sons, named Luoga, received a treasure gourd given by his mother, a fairy, and a rich man came to snatch the gourd. In the process of Luoga competing with the rich man for the treasure gourd, the house was on fire. The fire destroyed the Aini written words in the bamboo house, so the couple had to embroider the only memorized Aini written words on Hani costumes, called "ABO".[3] "ABO" in Hani Language is the meaning of written words. The patterns on behalf of the written words used to be very mysterious and exquisite. "Figure 1" shows the embroidery pattern "ABO" pattern on the back of the women's clothing of Aini branch in Xishuangbanna. 


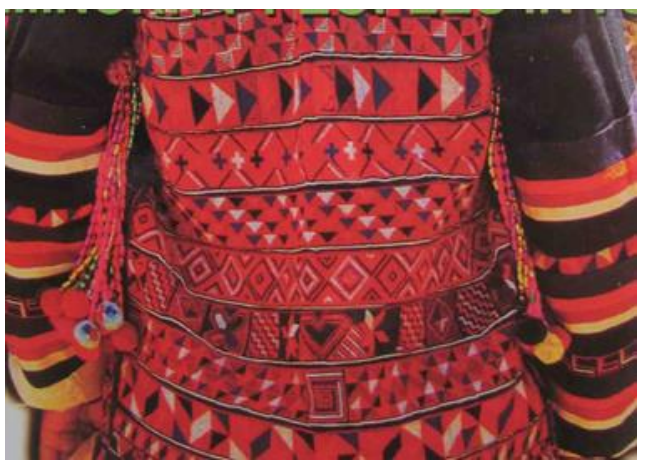

Figure 1 "ABO" pattern embroidered on Hani Costume.

\subsection{The Connotation of Visual Language of Hani Costume Patterns}

After studying the function of visual language of Hani costume pattern, we should also study its connotation. The meaning of Hani costume patterns has become the common understanding of Hani people. These patterns convey relatively fixed meanings in the context of Hani culture. Hani costume pattern is a simple symbol refined by Hani ancestors. And these symbols can refer to some specific connotations. This paper summarizes and interprets the connotation of some key Hani

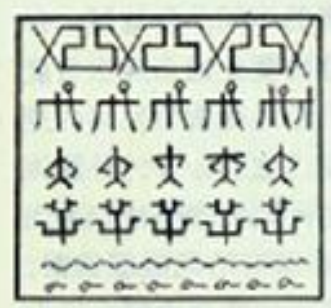

costume patterns. In his works, scholar Wanzhi Yang recorded and explained in detail the meaning of the patterns in "ABO". In the picture on the left ("Figure 2"), the sun and the moon, mice, people, trees, rivers and snakes are shown from top to bottom. In the picture on the right, the moon, the sun, the moon, the sun and the sun are in turn. The patterns in the picture can be seen as repeated words, "X" represents the sun, the crossed lines symbolize the sun's light, and the pattern adjacent to the sun is the moon. In the thought of Hani primitive worship, both the sun and the moon are sacred. There are a lot of different patterns about the sun and the moon in "ABO". The changes of the sun and the moon in the sky are directly related to the Hani ancestors' marriage, funeral, farming, festivals and calendar. Hani people believe that all things originate from the sun, and the soul will go to the moon after death. The worship of the sun and the moon is essentially a primitive religion.[4] The other patterns in "ABO" show the close relationship between mice, snakes and human beings in the life of Hani ancestors. The wave line represents the river, which shows the habits of Hani people living by water.

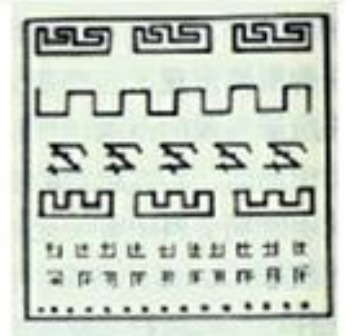

Figure 2 "ABO" pattern arranged by scholar Wanzhi Yang. [5]

Hani ancestors love the nature and are full of life interest. They embroider things on their clothes, such as owl eye pattern, dog tooth pattern, etc., which shows the animism thought of all things in Hani primitive religion. Dogs have the identity of protectors in Hani culture, and dog blood can drive away demons. Therefore, from the perspective of Hani people, dog tooth patterns have the meaning of driving away demons. As shown in "Figure 3", dog teeth patterns on Hani costumes have the same function. Owl eye pattern also represents the meaning of exorcism, so some children's hats are embroidered and beaded owl eye patterns for protection. The epic "Hani ape Cong Po Po" records that after the first settlement in Raluopuchu, the Hani people met with the plague and then moved away. The Hani people have gone through many arduous migrations from Nomaamei to Seazuoniang, Guhamicha, to Ailao Mountain and Wuliang Mountain.[6] On the way to migration, they met the Silver Pheasant. When Hani people saw the beauty, freedom and happiness of the Silver Pheasant, they took the Silver Pheasant as the symbol of their ethnic group, and hoped that they would live a free and happy life like the Silver Pheasant. The content mentioned above is the connotation of visual language of Hani costume patterns, which represents the traditional consciousness of Hani people. It is also the main content of visual language communication of Hani costume patterns. 


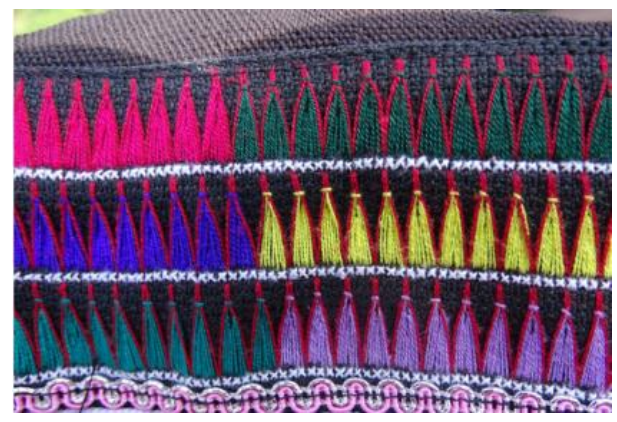

Figure 3 Dog teeth pattern on Hani's costume.

\subsection{Aesthetics of Visual Language of Hani Costume Patterns}

With the change of history, the Hani people can not recognize the original word "ABO" from the current clothing, let alone interpret the meaning of the text through these words, and some patterns have been simplified. Decorative patterns do not have independent meaning, but the significance of its dissemination is more important. The visual language of Hani costume pattern has unique

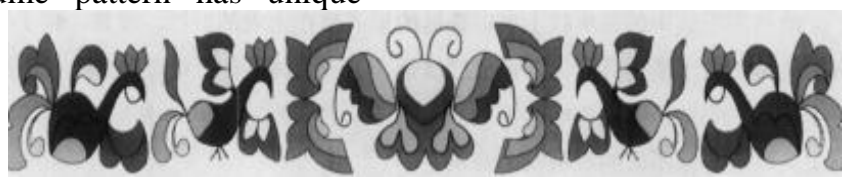

Figure 4 The pattern of the belt of the Hani women's coatume in Lvchun County.

\section{THE TRANSMISSION OF VISUAL LANGUAGE OF HANI COSTUME PATTERNS}

In fact, the visual language of Hani costume patterns is a "virtual language", rather than the entity language in our usual sense. The production process of visual language is that the user transforms the concrete or abstract graphic elements into communicative language symbols in the abstract way of language, and uses them for communication. The visual language of Hani costume patterns has its unique communication connotation, which is processed by the communication subject and then transmitted to the audience (communication object). Now how the visual language of Hani costume pattern is spread will be introduced.

\subsection{The Characteristics of Visual Language of Hani Costume Patterns}

The visual language of Hani costume pattern is a kind of symbolic language which presents after beauty, which is also an important dimension of its visual language communication content.

The visual language of Hani costume pattern has the beauty of image. The images of Hani costume patterns are mostly imitations and records of some beautiful objects. These patterns are vivid, concise and comprehensive, and have the beauty of images on patterns. There are many colors in the visual language of Hani costume patterns, with black, white, blue as the background colors, and red, yellow, green, purple and other main colors, with a strong color beauty. Hani costume pattern visual language follows the rule of formal beauty, often using two-way continuous composition, there are many symmetrical patterns, balanced composition. Hani costume pattern visual language pays attention to the rules of formal beauty, unconventional. As shown in "Figure 4", the pattern of the belt of the Hani women's in Lvchun county is a group of continuous patterns composed of butterflies and birds, arranged symmetrically and unified.[5] 
has the important difference in the form with the reappearance pattern.

From the perspective of the law of visual art, performance and reproduction are both the methods of visual art creation. They complement each other and influence each other. Both of them have their own characteristics and are indispensable, forming a variety of visual language forms of Hani costume patterns.

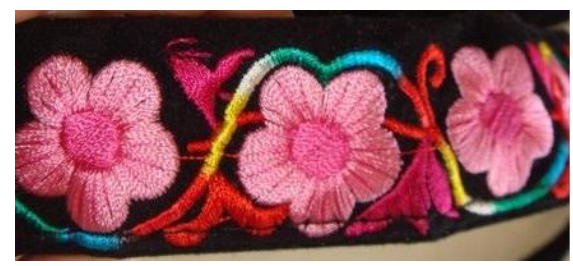

Figure 5 Plum blossom pattern on the belt of Yuanyang Hani women's costume.

\subsection{The Communication Process of Visual Language of Hani Costume Patterns}

From the perspective of communication science, media is the material and carrier of information exchange behavior between people or between man and machine. The research of information science shows that the information that people communicate with each other is the movement state and change mode of objective things perceived or described by the subject. The essence of media is the technical means of human society. Today's media are electronic devices, intelligent terminals and so on. In the context of Hani costume pattern visual language, the media is Hani costume.

The transmission process of visual language of Hani costume patterns can be shown in "Figure 6". After the communication subject (information source) transmits the communication content to the communication object (audience), both the communication subject and the communication object have the communication content, rather than the loss of information. The subject and object of communication here is not a chivalrous individual, but a broad group. If people want to spread these contents, they must have a certain media. The costume of Hani nationality serves as the carrier of this media, and the patterns on the costume of Hani nationality are the internal transmission of the media. The process of disseminating these information does not end with the information obtained by the communication object, but the communication subject (information source) and communication object (audience) have a common understanding of the content of communication.

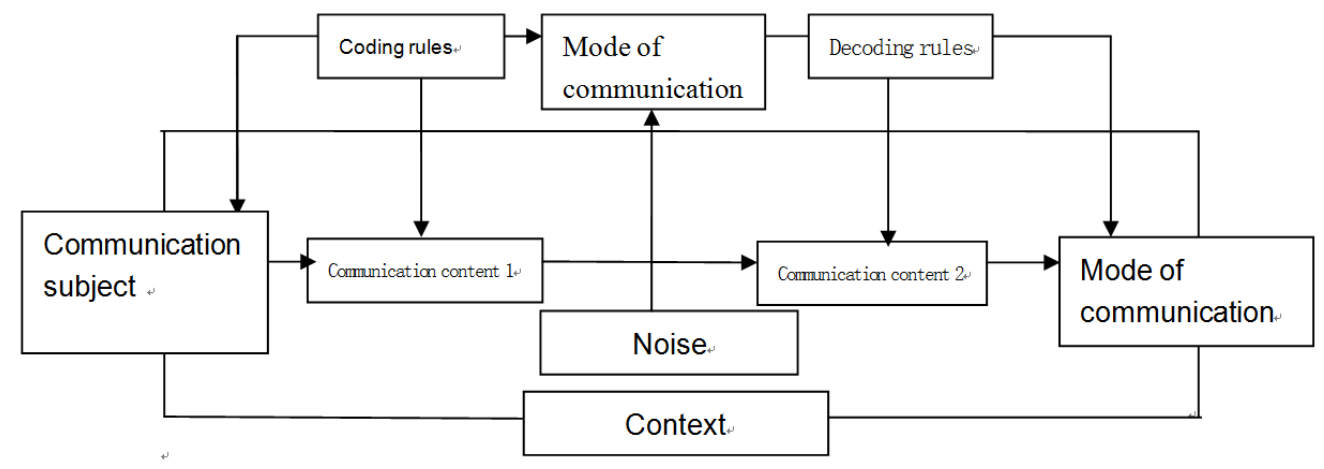

Figure 6 Transmission process of visual language of Hani costume patterns.

We take the square pattern of "ABO" on the back of Hani women's costume as an example to illustrate the transmission process of visual language of Hani costume patterns. First of all, the communication subject of the visual language is the Hani people who make the costume patterns of Hani nationality, and the communication objects are the people who can see the patterns. The people who saw these patterns were the ancestors who lived in the Hani area in the past, and now they are the people who see these costumes. The main body of the communication content disseminates the meaning they want to express through the Hani costumes, which is the media, to the communication object (audience), so that the audience can understand the content to be expressed. On the one hand, these contents are the aesthetic feelings of Hani people, which convey the geometric beauty connotation with square pattern in "Figure 1", on the other hand, these patterns have the function of dress decoration, and convey the hope of Hani people for happiness and auspicious. 
Finally, the connotation of the other's shape pattern of the communication subject (source) and the communication object (audience) has a common understanding.

The communication subject (source) transforms the meaning of praying for good luck and safety into visual language through its own unique coding method, and conveys it through the carrier of costume patterns. In the process of communication, due to the different cultural background and environment of the communication object, the information received by the audience and the information sent by the communication subject will be lost, which is caused by the noise in the communication process.

From the communication process of Hani costume pattern visual language, its communication characteristics can be summarized. After studying this communication process, we can research the connotation of Hani costume pattern visual language better, and also study its aesthetic characteristics, which can facilitate our cultural heritage protection of Hani costume pattern visual language, and also can draw inspiration from traditional cultural art.

\subsection{The Visual Language of Hani Costume Pattern Is a Complex Communication}

In the communication process of some visual language, the communication subject releases information, the communication object receives the information, the communication subject and the communication object abide by strict decoding rules, and the communication content is strictly transmitted to the audience, which is a one-way communication mode. Some visual language has its coding rules and context in the process of communication. The communication object interprets the communication content according to its own decoding rules. The communication of visual language of Hani costume patterns is a kind of complex communication. The so-called compound communication refers to a way of communication that takes the coding rules, decoding rules and context into consideration. In many cases, the communication subject and the audience overlap, that is, the communication subject and the receiver of the visual language are same. In the process of visual language communication of Hani costume patterns, it is often found that the coding rules adopted by the communication subject and the communication object are not completely consistent, or the communication object does not understand the rules adopted by the sender, or a large amount of noise is generated in the transmission process of visual language, which will also affect and interfere with the transmission effect The content of the original communication will be different. The visual language of Hani costume pattern is a complex communication, which considers coding rules, decoding rules, context and noise together.

\section{CONCLUSION}

From the perspective of the famous communication theory "5W mode", this paper analyzes and studies the communication of visual language of Hani dress patterns. It is concluded that the communication subject (source) of visual language of Hani dress patterns is Hani people, and its communication objects (audience) are people wearing Hani costumes and people who see these costumes. This paper analyzes the content and process of its communication from three aspects of function, connotation and aesthetics, and concludes that the communication process of the visual language is compound. On the basis of this research, we can better study the connotation, symbolic characteristics and aesthetic value of Hani clothing pattern visual language. This is conducive to the cultural heritage protection of Hani clothing pattern visual language, and can draw inspiration from minority culture and carry forward traditional culture.

\section{AUTHORS' CONTRIBUTIONS} Li.

This paper is independently completed by Yang

\section{REFERENCES}

[1] Sida Li, "An introduction to Digital Media Arts" Tsinghua university pressOct.2006, pp.6.

[2] Yangyang Tan. Research on the costume pattern art of Hani nationality. [D] Kunming University of science and technology, 2007, pp20-23

[3] Yang Li, Research on visual language of Hani costume patterns, [D] Kunming University of science and technology, June 2011, pp. 11-12.

[4] Wanzhi Yang, Divinity consciousness in Hani costumes, Journal of Yunnan University for nationalities, Vol. 04, 1988, pp. 58. 
[5] Wanzhi Yang, Divinity consciousness in Hani costumes, Journal of Yunnan University for nationalities, Vol. 04, 1988, pp. 59.

[6] Epic, Hani ape Cong Po Po, author unknown. 